\title{
Effects of salinity, commercial salts and water types on cultivation of the cryptophyte microalgae Rhodomonas salina and the calanoid copepod Acartia tonsa
}

Jepsen, Per Meyer; Thoisen, Christina Vinum; Carron-Cabaret, Thibaut; Pinyol Gallemi, Aleix; Nielsen, Søren Laurentius; Hansen, Benni Winding

Published in:

Journal of the World Aquaculture Society

DOI:

10.1111/jwas. 12508

Publication date:

2019

Document Version

Peer reviewed version

Citation for published version (APA):

Jepsen, P. M., Thoisen, C. V., Carron-Cabaret, T., Pinyol Gallemi, A., Nielsen, S. L., \& Hansen, B. W. (2019).

Effects of salinity, commercial salts and water types on cultivation of the cryptophyte microalgae Rhodomonas salina and the calanoid copepod Acartia tonsa. Journal of the World Aquaculture Society, 50(1), $104-118$. https://doi.org/10.1111/jwas.12508

\section{General rights}

Copyright and moral rights for the publications made accessible in the public portal are retained by the authors and/or other copyright owners and it is a condition of accessing publications that users recognise and abide by the legal requirements associated with these rights.

- Users may download and print one copy of any publication from the public portal for the purpose of private study or research.

- You may not further distribute the material or use it for any profit-making activity or commercial gain.

- You may freely distribute the URL identifying the publication in the public portal.

\section{Take down policy}

If you believe that this document breaches copyright please contact rucforsk@kb.dk providing details, and we will remove access to the work immediately and investigate your claim. 


\title{
Effects of Salinity, Commercial Salts, and Water Type on Cultivation of the Cryptophyte Microalgae Rhodomonas salina and the Calanoid Copepod Acartia tonsa
}

\author{
Per M. Jepsen ${ }^{1}{ }^{1}$ and Christina V. Thoisen \\ Department of Science and Environment, Roskilde University, Universitetsvej 1, PO Box 260, \\ DK-4000 Roskilde, Denmark \\ Thibaut Carron-Cabaret \\ Ecole Polytechnique Universitaire de Montpellier, Place Eugène Bataillon, 34095 Montpellier, \\ France \\ Aleix Pinyol-Gallemí (iD \\ National Institute for Aquatic Resources, Technical University of Denmark, Jagersborg Alle 1, \\ 2920 Charlottenlund, DK-2800 Lyngby, Denmark \\ Søren L. Nielsen and Benni W. Hansen \\ Department of Science and Environment, Roskilde University, Universitetsvej 1, PO Box 260, \\ DK-4000 Roskilde, Denmark
}

\begin{abstract}
Marine aquaculture facilities positioned far from the sea need access to seawater (SW); hence, commercial salts are often the chosen solution. In marine hatcheries, most fish larvae require live feed (zooplankton) that are in turn fed with microalgae. The objective of this research was to investigate the applicability of commercial salts and clarify the potential effects on the cultivation of the microalga Rhodomonas salina and the copepod Acartia tonsa. Three commercial salts were tested, Red Sea Salt (RS), Red Sea - Coral Pro Salt (CP), and Blue Treasure Salt. $R$. salina was cultured at salinities of 10,20 , and 30 psu resulting in equal growth rates at salinities 20 and 30 in $\mathrm{SW}$ and RS mixed with deionized (DI) water. The optimum salinity for $R$. salina was 29 psu. For A. tonsa eggs, we observed highest hatching success in 30 psu with CP or RS mixed with DI water. The egg hatching success was not affected by salinities 15-40 and optimal hatching was obtained at 27 psu. Results confirm it was possible to use commercial salts for rearing of both $R$. salina and $A$. tonsa, widening the application of these species for aquaculture facilities without access to $\mathrm{SW}$.
\end{abstract}

\section{KEYWORDS}

commercial salts, development stage progression, optimal algal growth, optimal copepod egg hatching success, salinity

The success of marine larval rearing is highly dependent on high-quality food for the first feeding of fish larvae (Dhert et al. 2001; Turingan et al. 2005). Traditionally, rotifers and subsequently Artemia are used as live feed, although copepods are required for larvae of some fish

\footnotetext{
${ }^{1}$ Correspondence to: pmjepsen@ ruc.dk
}

species (Shields et al. 1999; Mahjoub et al. 2013; Abate et al. 2015).

Most copepods depend on microalgae for food, preferably those with high amounts of long-chain fatty acids together with contents of essential fatty and amino acids. The cryptophyte Rhodomonas has been shown to be a promising candidate as food algae within aquaculture, 
JEPSEN ET AL.

TABLE 1. Elemental composition of salts in the water types used in the experiment.

\begin{tabular}{|c|c|c|c|c|c|c|c|c|c|}
\hline & FW & SW & RS & $\mathrm{CP}$ & BT & MW & $\mathrm{RS}^{\mathrm{a}}$ & $\mathrm{CP}$ & BT \\
\hline PSU & 0 & 35 & 35 & 35 & 35 & & 35.5 & 35 & 35 \\
\hline \multicolumn{10}{|c|}{ Major cations $(\mathrm{mmol} / \mathrm{kg})$} \\
\hline $\mathrm{Na}^{+}$ & 13 & 445.3 & 314.9 & 417.9 & 400.3 & 23.0 & N/A & N/A & 413.0 \\
\hline $\mathrm{K}^{+}$ & 0.1 & 10.1 & 31.4 & 10.1 & 10.6 & 39.1 & 10.0 & 10.2 & \\
\hline $\mathrm{Mg}^{2+}$ & 0.6 & 51.7 & 168.6 & 51.7 & 55.9 & 24.3 & 52.7 & 57.2 & 58.6 \\
\hline $\mathrm{Ca}^{2+}$ & 2.4 & 10.6 & 2.9 & 12.0 & 11.5 & 40.1 & 10.7 & 11.6 & 11.0 \\
\hline Sum & 5.0 & 517.7 & 517.9 & 491.7 & 478.4 & & N/A & N/A & 492.5 \\
\hline \multicolumn{10}{|l|}{ Major anions (mmol/kg) } \\
\hline $\mathrm{Cl}^{-}$ & 0.76 & 573.4 & 567.4 & 528.8 & 521.6 & 35.5 & N/A & N/A & 493.0 \\
\hline $\mathrm{SO}_{4}{ }^{2-}$ & 0.97 & 28.1 & 75.4 & 69.9 & 69.9 & 32.1 & N/A & N/A & 74.8 \\
\hline $\mathrm{Br}^{-}$ & N/A & Trace & N/A & 0.8 & N/A & 79.9 & N/A & N/A & 0.4 \\
\hline Sum & 1.7 & 601.4 & 642.7 & 599.6 & 591.4 & & N/A & N/A & 568.1 \\
\hline $\mathrm{HCO}_{3}{ }^{-}($at $\mathrm{pH}$ 6.0) & 2.95 & N/A & N/A & N/A & N/A & 61 & N/A & N/A & N/A \\
\hline \multicolumn{10}{|l|}{ Nutrients $(\mu \mathrm{mol} / \mathrm{kg})$} \\
\hline $\mathrm{PO}_{4}: \mathrm{P}$ & Trace & 96.8 & 0.1 & N/A & N/A & 31.0 & N/A & N/A & N/A \\
\hline $\mathrm{NO}_{3}: \mathrm{N}$ & 0.2 & 7.1 & 0.2 & N/A & N/A & 14.0 & N/A & N/A & N/A \\
\hline $\mathrm{NH}_{4}: \mathrm{N}$ & Trace & 71.4 & Trace & 36.5 & 33.8 & 14.0 & N/A & N/A & N/A \\
\hline \multicolumn{10}{|l|}{ Trace $(\mu \mathrm{mol} / \mathrm{kg})$} \\
\hline Мо & Trace & Trace & Trace & N/A & N/A & 95.9 & N/A & N/A & N/A \\
\hline $\mathrm{Cu}$ & Trace & Trace & Trace & N/A & N/A & 63.5 & N/A & N/A & N/A \\
\hline $\mathrm{Zn}$ & Trace & 2,4 & 0.1 & N/A & N/A & 65.4 & N/A & N/A & N/A \\
\hline Mn & Trace & 0.7 & Trace & N/A & N/A & 54.9 & N/A & N/A & N/A \\
\hline $\mathrm{Fe}$ & Trace & 2,9 & Trace & N/A & N/A & 55.8 & N/A & N/A & Trace \\
\hline B & Trace & 3.7 & 0.6 & N/A & N/A & 10.8 & N/A & N/A & 0.5 \\
\hline
\end{tabular}

$\mathrm{BT}=$ Blue Treasure Salt; $\mathrm{CP}=$ Red Sea - Coral Pro Salt; FW = tap water; $\mathrm{MW}=$ molecular weight, $\mathrm{g} / \mathrm{mol}$; RS = Red Sea Salt; SW = seawater.

${ }^{a}$ Levels according to the manufacturer, note RS is $35.5 \mathrm{psu}$.

for oysters (González-Araya et al. 2012), blue mussels (Riisgård et al. 2011), and copepods (Støttrup and Jensen 1990; Knuckey et al. 2005; Ohs et al. 2010; Zhang et al. 2013; Arndt and Sommer 2014). Rhodomonas has also been used in paste form for rotifers (Guevara et al. 2011) and copepods (T. A. Rayner, Roskilde University, Roskilde, unpublished data), and more importantly, it has a suitable cell size for all developmental stages of Acartia tonsa (Berggreen et al. 1988).

Acartia tonsa is a euryhaline cosmopolitan copepod often associated with the neritic zone, tolerating salinities from 5 to 72 psu (Paffenhöfer and Stearns 1988; Cervetto et al. 1999; Chinnery and Williams 2004; Højgaard et al. 2008; Ohs et al. 2009). A. tonsa has been grown in laboratory cultures in seawater (SW) since the 1980s (Støttrup et al. 1986). Already in 1999, Kusk and Wollenberger (1999) suggested a synthetic saltwater medium for toxicity tests and cultures of
A. tonsa. They cultured both Rhodomonas salina and A. tonsa for 8 mo in a home-blended synthetic medium. Although this synthetic saltwater is well proven to work with $R$. salina and A. tonsa, the recipe is rather complex to mix. Therefore, a ready-to-mix, off-the-shelf, commercially available salt is more relevant to test on cultures of $R$. salina and A. tonsa. In the present study, we tested the effects of three different commercial salts with different origin and composition (Table 1), and natural SW as a control, on $R$. salina growth rate and A. tonsa egg hatching success and subsequent development stage progression. Extensive ranges of salinities (from 0 to 70 ) were used to evaluate the hatching success of A. tonsa eggs to further test the phenotypic plasticity of the embryos in the eggs. Thus, we evaluated commercial sea salt mixes on all stages of cultures of $R$. salina and A. tonsa to reduce dependency on natural SW. 


\section{Materials and Methods}

All experiments were conducted in a walk-in temperature-controlled room at $17 \pm 2 \mathrm{C}$ at Roskilde University, Denmark.

\section{Water Quality}

In the copepod development experiment, dissolved oxygen and $\mathrm{pH}$ were measured each morning on Days $0,4,7$, and 10 in each bottle using a handheld Oxyguard Polaris 2 for oxygen, and $\mathrm{pH}$ with an Oxyguard handy $\mathrm{pH}$ portable $\mathrm{pH} /$ Redox meter (Oxyguard International A/S, Farum, Denmark). The temperature was measured in the temperature-controlled room using HOBO Data Loggers (UA-002-64 HOBO Pendant Temp/Light, $64 \mathrm{~K}$, Bourne, MA), set to log every hour during the entire experiment.

Samples for determination of inorganic nutrients, total ammonia nitrogen (TAN), nitrate $\left(\mathrm{NO}_{3}{ }^{-}\right)$, and nitrite $\left(\mathrm{NO}_{2}^{-}\right)$were sampled from each treatment at the end of the population development experiment. Determinations of TAN levels were analyzed with a MERCK Spectroquant ${ }^{\circledR}$ (Darmstadt, Germany) test 1.14752, $\mathrm{NO}_{3}{ }^{-}$with test 1.14942 , and $\mathrm{NO}_{2}{ }^{-}$with test 1.14776. Analyses were carried out using a MERCK Spectroquant NOVA 60 (Darmstadt, Germany).

Three commercial salts were analyzed, Red Sea Salt (RS), Red Sea - Coral Pro Salt (CP), and Blue Treasure Salt (BT), for their major cations and anions, nutrient compounds, and trace elements. Furthermore, the tap water, used to mix with the commercial salts, was also analyzed for major cations and anions, nutrient compounds, and trace elements, as well as inorganic carbon (Gran titration; Stumm and Morgan 1996). All commercial salts were mixed at $35 \mathrm{psu}$ to be comparable with the SW. The cations and anions, nutrient compounds, and trace elements were analyzed by an ion chromatograph (Dionex ICS-1100, ThermoFisher Scientific, Roskilde, Denmark). The cations and anions were analyzed separately. The cations were analyzed using a DionexIonPacTMCS12A column, with eluent $20 \mathrm{mM} \mathrm{H}_{2} \mathrm{SO}_{4}$. The anions were analyzed using a DionexIonPacTMAS14A column, with eluent $8 \mathrm{mM} \quad \mathrm{Na}_{2} \mathrm{CO}_{3} / 1 \mathrm{mM}$ $\mathrm{NaHCO}_{3}$.

\section{Saltwater}

The RS, CP, and BT used in experiments were all tested against a control of $0.2-\mu \mathrm{m}$ filtrated SW that was usually used for successful production of both $R$. salina and A. tonsa at Roskilde University and DTU-Aqua (Støttrup et al. 1986; Drillet et al. 2006a; Jepsen et al. 2007). This SW originates from $30-\mathrm{m}$ depth in the outer parts of the Kattegat $\left(57^{\circ} \mathrm{N}\right.$, Denmark), with $35 \mathrm{psu}$. The salts were mixed with either tap water from Taastrup, Denmark (Table 1), or deionized (DI) water from Roskilde University, Denmark. Tap water in Denmark follows the legislation in BEK nr. 802 (Drikkevandsbekendtgørelsen 2016). Salinities were mixed to different psu by weighing salt on an AE163 Mettler scale (Glostrup, Denmark) and adding it to either tap or DI water to the psu given in the experimental setup. The mean salt strength was $30-35$ psu for the SW used in the laboratory at Roskilde University. The salts and SW were left for at least $1 \mathrm{wk}$ and mixed to ensure total dissolution of the commercial salt products. Salinity strengths were tested and adjusted prior to the experiments with a handheld refractometer with a resolution of 0.5 psu (ATAGO, Tokyo, Japan).

The salts RS and CP are both from the same producer, Red Sea (RedSea 2017). The salts are manufactured by natural evaporation of SW from the Red Sea, through three shallow ponds, increasing the salinity from 40 to $250 \mathrm{psu}$. During an evaporation process, sodium chloride crystals with ions of magnesium and potassium are formed. Thereafter, the salts are washed, dried, and finally RS and CP are elevated to different levels of calcium, magnesium, potassium, and other trace elements by the manufacturer (RedSea 2017).

The BT is a synthetic salt created from underground SW from the BoHai Bay in China. The manufacturing process is, according to the producer, first evaporation of the underground SW. Thereafter, the supernatant is removed and further evaporated in a pressure cooker. Then the refined sea salt is sieved and smashed before addition of trace elements and elevation of calcium, magnesium, and potassium by the manufacturer (Aquaseasalt 2017). 


\section{Cultivation of $\mathrm{R}$. salina}

For all experiments, $R$. salina strain K-1487, Scandinavian Culture Collection of Algae \& Protozoa, was used. Before the experiments, $R$. salina was cultured at the exponential growth phase in 2-L round-bottom glass bottles, with $0.2-\mu \mathrm{m}$ filtered SW fertilized with a modified f/2 media without cobalt (Guillard and Ryther 1962; Christina V. Thoisen, Roskilde University, Roskilde, unpublished data), at $17 \pm 2 \mathrm{C}$ and under constant light at $80 \mu \mathrm{mol} / \mathrm{m}^{2} / \mathrm{sec}$ photosynthetically active radiation (PAR). The light intensity was measured with a Hansatech Instrument LTD Quantitherm light meter QRT1 (Norfolk, UK).

\section{Optimal Salinity for Growth of R. salina}

To investigate the optimal salinity for $R$. salina cultivation, an experimental setup was conducted in 0.5 -L round-bottom glass bottles. The light intensity was between 100 and $115 \mu \mathrm{mol} / \mathrm{m}^{2} / \mathrm{sec}$ PAR and nutrients were added in saturation (modified $f / 2$ media). The experiment was started with $R$. salina grown as described earlier and was inoculated into four replicate controls of 35 psu $0.2-\mu \mathrm{m}$ filtrated SW and four replicate RS mixed with DI water to an ion strength of $35 \mathrm{psu}$. All replicates were initiated with a cell concentration of 50,000 \pm 1500 cells $/ \mathrm{mL}$. All replicates were sampled and the cell concentration was measured using an electronic particle counter (Beckman Multisizer 4e Coulter Counter (Brea, CA) equipped with a $100-\mu \mathrm{m}$ aperture tube). When the cell concentration reached 1 million cells $/ \mathrm{mL}$ or more, the algae were diluted to 50,000 cells $/ \mathrm{mL}$ in new salinity strengths of RSs by changing the salinity by \pm 5 psu. Hence, 35 psu was diluted into four new bottles with either 40 or 30 psu. This continued within the range from 35 to 0 and from 35 to $65 \mathrm{psu}$, respectively. For each of the salinities, growth rates were obtained and calculated by Equation (1).

$$
\mu=\frac{\ln N_{2}-\ln N_{1}}{t_{2}-t_{1}}
$$

where $\mu$ is the growth rate $(/ \mathrm{d}), N_{1}$ is the number of cells at $t_{1}$, and $N_{2}$ is the number of cells at time $t_{2}$, respectively. To describe the relationship between salinity and growth rate in $R$. salina, we used a three-parameter Gaussian model (SigmaPlot version 10.0 build 10.0.0.54, Systat software, Chicago, IL).

$$
f(x)=a e^{-0.05}\left(\frac{x-x_{0}}{b}\right)^{2}
$$

where $a$ is the height of the curves peak, $x_{0}$ is the center of the curves peak, and $b$ is the SD of the mean.

\section{Effect of Commercial Salts on R. salina Growth}

Rhodomonas salina growth rates were evaluated in SW and in commercial salts at 20 and 30 psu. Each treatment was replicated three times in 1-L round-bottom glass bottles with aeration. The experiment was conducted with a light intensity of $80 \mu \mathrm{mol} / \mathrm{m}^{2} / \mathrm{sec}$ PAR and with nutrients in excess (modified $\mathrm{f} / 2$ media) ( $\mathrm{Vu}$ et al. 2015). Growth rates were monitored each day, over $5 \mathrm{~d}$, in all treatments, by daily measuring cell concentration using an electronic particle counter. The growth rates were calculated by Equation (1). A three-factor PERMANOVA was used to evaluate the effects of commercial salts (Factor A), tap or DI water (Factor B), and salinity (Factor C) upon the growth rate of $R$. salina. Euclidian distances were used for the resemblance matrix and the procedure "permdisp" was used to test if the assumptions for a PERMANOVA were fulfilled. The program Primer 6 with the add-on PERMANOVA was used (PRIMER-E Ltd., Plymouth, UK).

\section{Cultivation of A. tonsa}

The experiment was initiated with cold-stored A. tonsa eggs harvested from cultures kept at Roskilde University. The origin of the particular copepod culture is the DFH.AT1 culture isolated in Øresund in 1981 (Støttrup et al. 1986). The $A$. tonsa cultures were kept at 35 psu SW, no light, $17 \pm 2 \mathrm{C}$, and fed a mono algal diet of $R$. salina (K-1487). The eggs were cold-stored by the method described by Drillet et al. (2006b), with the modification that the eggs were stripped of dissolved oxygen by bubbling with nitrogen gas, immediately after thoroughly cleaning 
with SW in successive filters (200 and $65 \mu \mathrm{m})$. This treatment was applied to optimize storage conditions.

\section{Optimal Salinity for A. tonsa Egg Hatching Success}

Fresh eggs harvested from our culture within $4 \mathrm{~h}$ of spawning were used to initiate the optimal salinity and hatching experiment. In this experiment, SW was used and either concentrated by evaporation ( $>35 \mathrm{psu})$ or diluted with DI water ( $<35 \mathrm{psu}$ ). Salinities were 0, 5, 10, 15, 20, 25, $30,35,40,50,55,60,65$, and 70 psu. Eggs were subsampled into $10 \times 20$ - $\mathrm{mL}$ petri dishes for each treatment using a 10-mL kip automate (NS 29.2/32 Witeg, Wertheim, Germany). Each petri dish was stocked with a mean of $60 \pm 3$ eggs. Hatching successes were obtained after $48 \mathrm{~h}$, by fixing nauplii and remaining eggs in $1 \%$ acid Lugol's solution and counted using a dissection microscope (SZ40 Olympus Optical $\mathrm{GmBH}$, Germany at $20 \times$ magnification). The relationship between egg hatching success of $A$. tonsa eggs and salinity was determined by fitting the data to Equation (2).

\section{Effect of Commercial Salts on A. tonsa Egg Hatching Success}

Cold-stored eggs were used to evaluate the effects of tap, DI water, salinity, and commercial salts on $48 \mathrm{~h}$ hatching success. Three different salinities were used: 10, 20, and $30 \mathrm{psu}$, mixed with either tap or DI water. An aliquot of $10-\mathrm{mL}$ water, adjusted to the relevant salinity, was subsampled into 10 replicate $20-\mathrm{mL}$ petri dishes for each treatment with a 10 -mL kip automate. Each Petri dish was stocked with a mean of $111 \pm 11$ eggs. Primer 6 was used to build a three-factor PERMANOVA design to statistically analyze the effects of commercial salts (Factor A), tap or DI water (Factor B), and salinity (Factor $\mathrm{C}$ ) on the A. tonsa egg hatching success.

\section{Effect of Commercial Salts on A. tonsa Development}

Three commercial salts mixed with DI water were tested as growth media for A. tonsa and compared with $0.2-\mu \mathrm{m}$ filtered $\mathrm{SW}$, all at $30 \mathrm{psu}$. For each treatment, four replicate $600-\mathrm{mL}$ bottles (Nalgene, ThermoFisher Scientific) were initiated with a total of $13,700 \pm 538$ cold-stored eggs/bottle. The eggs were subsampled with a 10-mL kip automate. For determination of initial hatching success, $10 \times 20-\mathrm{mL}$ petri dishes were subsampled for each of the eight treatments. The petri dishes were stocked with a mean of $217 \pm 4$ eggs/petri dish to determine initial hatching success. After $72 \mathrm{~h}$, the hatched nauplii and remaining eggs were fixed in $1 \%$ acid Lugol's solution and counted using a dissection microscope. By multiplying the initial egg numbers $(d 0)$ with the hatching success, the actual numbers of starting individuals in each of the treatments are derived (d3). Each day, all bottles were fed in excess with $R$. salina (>950 $\mu \mathrm{g} \mathrm{C/L}$ ) (Kiørboe et al. 1985; Berggreen et al. 1988). At Days 5, 8, and 11, each of the four replicate bottles for all treatments were subsampled with a $10-\mathrm{mL}$ kip automate. Animals from each subsample were fixated in $1 \%$ acid Lugol's solution and identified as either nauplii or copepodites/adults. At Day 14, the experiment was terminated and all animals were fixated, enumerated, and stage was determined. The enumerated animals from each treatment were used to estimate the instantaneous rates of mortality (Z/d) calculated using Equation (3) (Klein Breteler et al. 2004).

$$
N_{t}=N_{0} e^{-z t}
$$

where $N_{0}$ is the number of individuals at time 0 and $N_{t}$ is the number of individuals at time $t$. $N_{t}$ was corrected for sampling mortality using Equation (4) (Klein Breteler et al. 2004).

$$
\frac{V n^{-1}}{\left(V-v_{1}\right)\left(V-v_{2}\right) \ldots\left(V-v\left(n^{-1}\right)\right)}
$$

where $V$ is the volume of the experimental bottle, $v$ is the volume of the subsample, and $n$ is the rank number of the subsample.

The instantaneous rates of mortality were calculated for each of the four replicate bottles within each of the treatments and presented as 
a mean mortality during the total experimental time for the total population.

To estimate the time duration $(d)$ for change from nauplii to copepodites, data were divided into two fractions with nauplii as one fraction and copepodites as the other fraction. Plotting the developing fractions as a function of time showed where the majority of the population switched from nauplii to copepodites, because an intersection between the two lines happens. By assuming linearity between the lines in the intersection point, simple algebra can be used to solve the intersection point, and hence the time where the majority of the population was switching from nauplii to copepodites can be extracted.

Mortality, time for stage switch, and total population were each statistically tested for normal distribution and equal variances before further testing with a one-way ANOVA in SigmaPlot version 10.0 build 10.0.0.54 (Systat software).

\section{Results}

\section{Water Quality}

Mean dissolved oxygen was $5.65 \pm 0.67 \mathrm{mg}$ $\mathrm{O}_{2} / \mathrm{L}$, the mean $\mathrm{pH}$ was $8.12 \pm 0.04$, and the mean temperature was $15.7 \pm 0.3 \mathrm{C}$ during the experiment between all replicates. Mean concentrations of TAN were $0.06 \pm 0.05 \mathrm{mg} / \mathrm{L}$, mean $\mathrm{NO}_{3}{ }^{-}$at $0.42 \pm 0.20 \mathrm{mg} / \mathrm{L}$, and mean $\mathrm{NO}_{2}{ }^{-}$concentrations were all below a detection limit of $0.02 \mathrm{mg} \mathrm{L}^{-1}$ (Table 1).

The sum of major cations in RS resembled SW. Further high concentrations of $\mathrm{Mg}^{2+}$ was observed in RS. CP was the salt that was most similar to SW in terms of the composition of major cations. For major anions, all commercial salts (RS, CP, and BT) had twice as much $\mathrm{SO}_{4}{ }^{2-}$ concentrations than SW. SW contained high amounts of nutrients $\left(\mathrm{PO}_{4}: \mathrm{P}, \mathrm{NO}_{3}: \mathrm{N}\right.$, and $\mathrm{NH}_{4}: \mathrm{N}$ ) compared to the RS, CP, and BT. Trace elements were only detected in a small amount in SW and in RS but was below detection limit for both CP and BT.

\section{Optimal Salinity for R. salina}

The growth rate of $R$. salina was influenced by salinity, and the optimum growth rate was $1.13 / \mathrm{d}$ at $29.1 \pm 2.3 \mathrm{psu}$. The model fits were: peak $(a)=1.13 \pm 0.07, \mathrm{SD}(b)=28.86 \pm 3.52$, and center of peak $\left(X_{0}\right)=29.14 \pm 2.27(n=56$, $\left.r^{2}=0.67\right)$. The lowest growth rate was observed at each end of the salinity range at 0 and 55-65 psu. All salinities from 5 to $50 \mathrm{psu}$ had a growth rate higher than $0.8 /$ d (Fig. 1).

\section{Effect of Salts on R. salina Growth}

The effects of different salts showed that the $R$. salina growth rates in $\mathrm{SW}$ (from 1.11 to $1.21 / \mathrm{d})$ were statistically significantly different and higher than the growth rates in both $\mathrm{CP}$ (from 0.73 to $1.04 / \mathrm{d}$ ) and BT (from 0.83 to $1.03 / \mathrm{d})(P=0.01)$. When comparing salts prepared with tap water, $R$. salina grew better in SW (1.20/d at $20 \mathrm{psu}$ and $1.12 / \mathrm{d}$ at $30 \mathrm{psu})$ than in $\operatorname{RS}(0.94 / \mathrm{d}$ at $20 \mathrm{psu}$ and $0.93 / \mathrm{d}$ at $30 \mathrm{psu})$ $(P=0.009)$. Among the commercial salts, $R$. salina grew better in RS than in BT $(P=0.01)$. Comparing salts prepared with DI water revealed that $R$. salina grown in BT (1.02 and 1.03/d) had a significantly different lower growth rate than $R$. salina grown in both SW (1.21 and $1.11 / \mathrm{d})$ and $\operatorname{RS}(1.22$ and $1.19 / \mathrm{d})(P=0.01)$. Furthermore, the results from the three-factor PERMANOVA showed statistically significant differences among the growth rates depending on the type of commercial salt used $(P=0.0002)$ and the type of water used $(P=0.0008)$. There was no statistical effect of different salinities at 20 and 30 psu $(P=0.0579)$ (Fig. 2 and Table 2$)$.

\section{Optimal Salinity for A. tonsa Egg Hatching Success}

The salinity interval within which $A$. tonsa subitaneous eggs were capable of hatching ranged from 5 to $50 \mathrm{psu}$, with an optimum hatching success of $67.7 \%$ at $27.5 \pm 0.5 \mathrm{psu}$. The model fits are: peak $(a)=67.68 \pm 1.99$, SD $(b)=14.28 \pm 0.54$, and center of peak $\left(X_{0}\right)=27.51 \pm 0.54\left(n=170, r^{2}=0.81\right)$. Within the range from 15 to $40 \mathrm{psu}$, more than $50 \%$ of the eggs hatched (Fig. 3).

\section{Effects of Commercial Salts on A. tonsa Egg Hatching Success}

Eggs exposed to RS had the highest hatching success (from 40.2 to $67.9 \%$ ), closely followed 


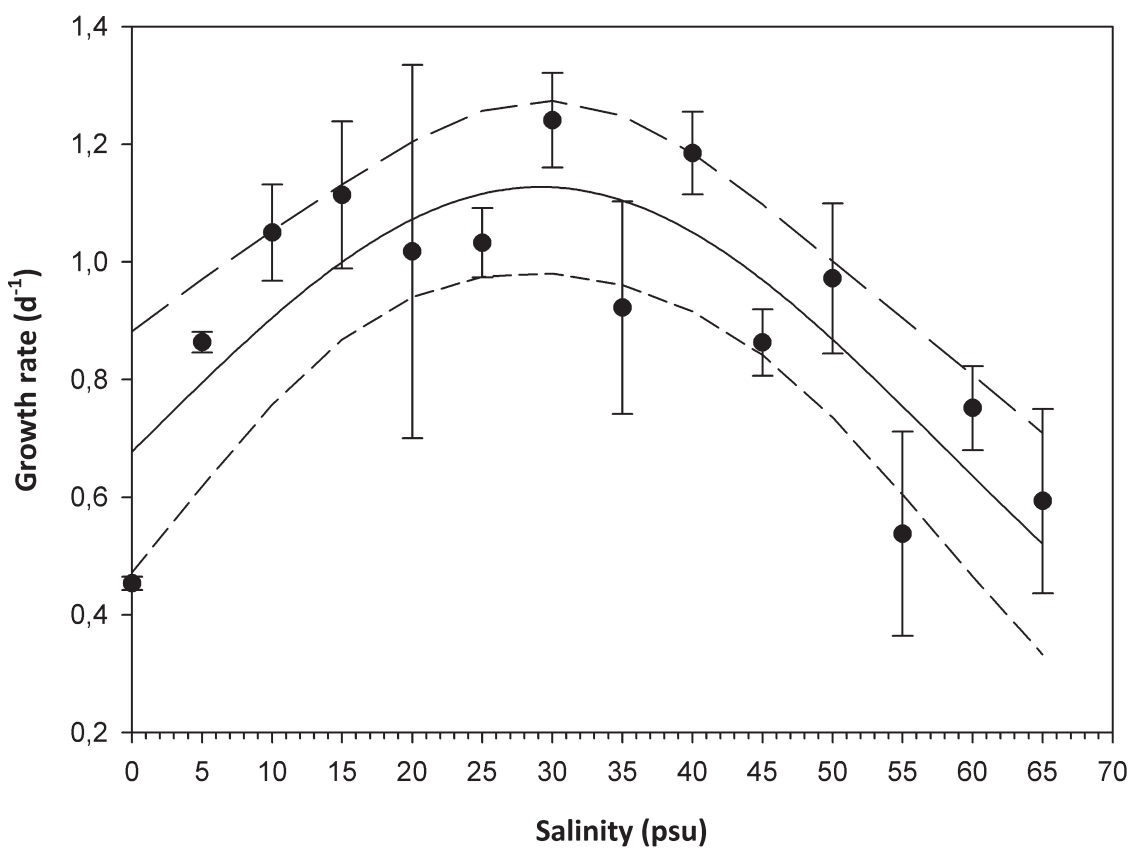

FIGURE 1. The optimum salinity for growth of $\mathrm{R}$. salina is 29.1 psu with a growth rate of 1.2/d. Symbols are mean \pm SE $(\mathrm{n}=4)$. Solid line is a three-parameter Gaussian fit, and dashed lines are the $95 \% \mathrm{CL}$.

by CP (38.5-60.9\%) (Fig. 4A-C and Table 3). The overall hatching success was lowest in BT $(25.3 \%$ in tap and $42.6 \%$ in DI water). The effects across all salinities confirmed this pattern where CP gave the highest hatching success regardless of whether tap $(34.0 \%)$ or DI water $(50.0 \%)$ was used for preparation and BT the lowest hatching success (Fig. 4D). In general, hatching success was higher in saltwater medium prepared with DI water than in tap water, except for at $30 \mathrm{psu}$ (Fig. 4A-C, gray bars). The same pattern was observed across all salinities (Fig. 4D) and across all salts (Fig. 4E). In terms of salinity, the best hatching success was achieved at 30 psu (Fig. 4C, E, F). The type of water used to prepare the saltwater medium also had an effect at salinities from 20 psu and below, where the hatching success was lower when salts were mixed with tap water than with DI water (Fig. 4A-C, E, F).

Effects of Commercial Salts on A. tonsa Mortality, Development, and Culture Densities

The highest mean mortality was observed $(17.7 \pm 1.6 \% / d)$ in the population exposed to BT and the lowest mean mortality was observed in SW (14.2 $\pm 0.4 \% / d)$ (Fig. 5).

The average shift in moulting time between the two major larval categories nauplii and copepodites for copepods in SW was $7.02 \pm 0.02 \mathrm{~d}$, followed by $\mathrm{CP}(6.99 \pm 0.04 \mathrm{~d}), \mathrm{RS}(6.97 \pm 0.06$ d), and BT (6.91 \pm 0.07 d) (Fig. 5).

The abundance showed the expected reverse pattern of mortality. The population with the highest survival rate was the one in SW with a mean of $1388 \pm 68$ individuals/L. The population with fewest animals at the end was the copepods exposed to BT, with a mean of $1167 \pm 464$ individuals/L (Fig. 5).

\section{Discussion}

Water Quality

We tested the water quality and the ions in different waters and salts to ensure the environmental comparability with our test organisms. Marcus et al. (2004) showed that dissolved oxygen concentrations of $1.5 \mathrm{mg} / \mathrm{L}$ did not affect the survival of $A$. tonsa; hence, we do not expect dissolved oxygen concentrations to 

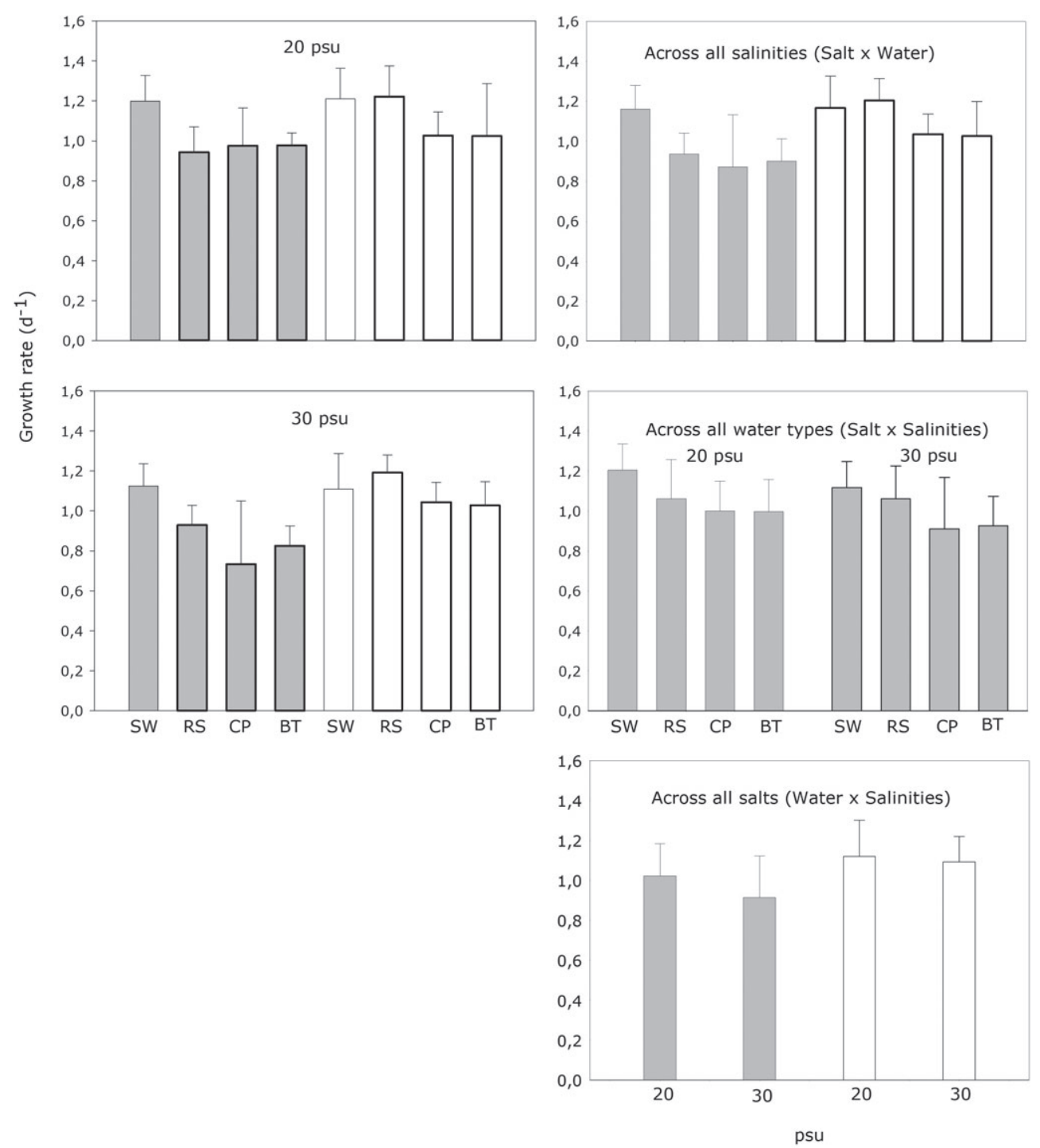

FIGURE 2. Growth rate of R. salina as a function of commercial salt, water type, and salinity. Gray bars are salts mixed with ordinary tap water and white bars are salts diluted in deionized water. Bars are mean $\pm S D(\mathrm{n}=3$ or 4$)$. The two left graphs show single effects, whereas the three right graphs show the mixed effects.

affect results of this study (ca. $5 \mathrm{mg} / \mathrm{L}$ ). The $\mathrm{pH}$ level that copepods were exposed to in this study was 8.12 , which in itself is not harmful and within the range of other experiments (Drillet et al. 2008; Jepsen et al. 2015; Hansen et al. 2017). TAN in the current experiment was $60 \mu \mathrm{g} / \mathrm{L}$, whereas only $3-4 \%$ was $\mathrm{NH}_{3}$ due to the $\mathrm{NH}_{3} / \mathrm{NH}_{4} \mathrm{pH}$-dependent equilibrium. Jepsen et al. (2015) has shown that this concentration of $2.4 \mu \mathrm{g} \mathrm{NH}_{3} / \mathrm{L}$ has no effects on $A$. tonsa nauplii or adults. $\mathrm{NO}_{2}{ }^{-}$was below the detection limit of $0.002 \mathrm{mg} / \mathrm{L}$ and is therefore not expected to have reached toxic levels for $A$. tonsa. $\mathrm{NO}_{3}{ }^{-}$was $0.42 \mathrm{mg} / \mathrm{L}$ in the current experiment (Table 1). The three salts, RS, CP, and BT, had two different origins, RS and $\mathrm{CP}$ were evaporated SW and BT was synthetically manufactured underground SW. Table 1 shows that RS has differences in major anion and cations with higher concentrations of $\mathrm{Mg}^{2+}$ and $\mathrm{SO}_{4}{ }^{2-}$, which was 
TABLE 2. PERMANOVA results showing effects on algal growth rates. ${ }^{a}$

\begin{tabular}{lcccccc}
\hline Source & df & SS & MS & Pseudo- $F$ & $P($ perm $)$ & Unique perms \\
\hline Salt & 3 & 13.1740 & 4.3914 & 67.698 & $\mathbf{0 . 0 0 0 2}$ & 9955 \\
Water & 1 & 8.9301 & 8.9301 & 13.767 & $\mathbf{0 . 0 0 0 8}$ & 9813 \\
Salinity & 1 & 2.3784 & 2.3784 & 36.665 & 0.0579 & 9846 \\
Salt $\times$ water & 3 & 4.2008 & 1.4003 & 2.1586 & 0.1100 & 9953 \\
Salt $\times$ salinity & 3 & 0.4795 & 0.1599 & 0.2464 & 0.8604 & 9946 \\
Water $\times$ salinity & 1 & 0.9465 & 0.9465 & 1.4591 & 0.2318 & 9827 \\
Salt $\times$ water $\times$ salinity & 3 & 1.5656 & 0.5219 & 0.8045 & 0.4968 & 9958 \\
Residual & 44 & 28.5420 & 0.6487 & & & \\
Total & 59 & 59 & & & &
\end{tabular}

${ }^{a}$ Results from a three-way factual Permanova analyses. Effects of commercial salts and the water the salts are mixed and diluted in were observed. Statistical significances are marked in bold font $(P<0.05)$.

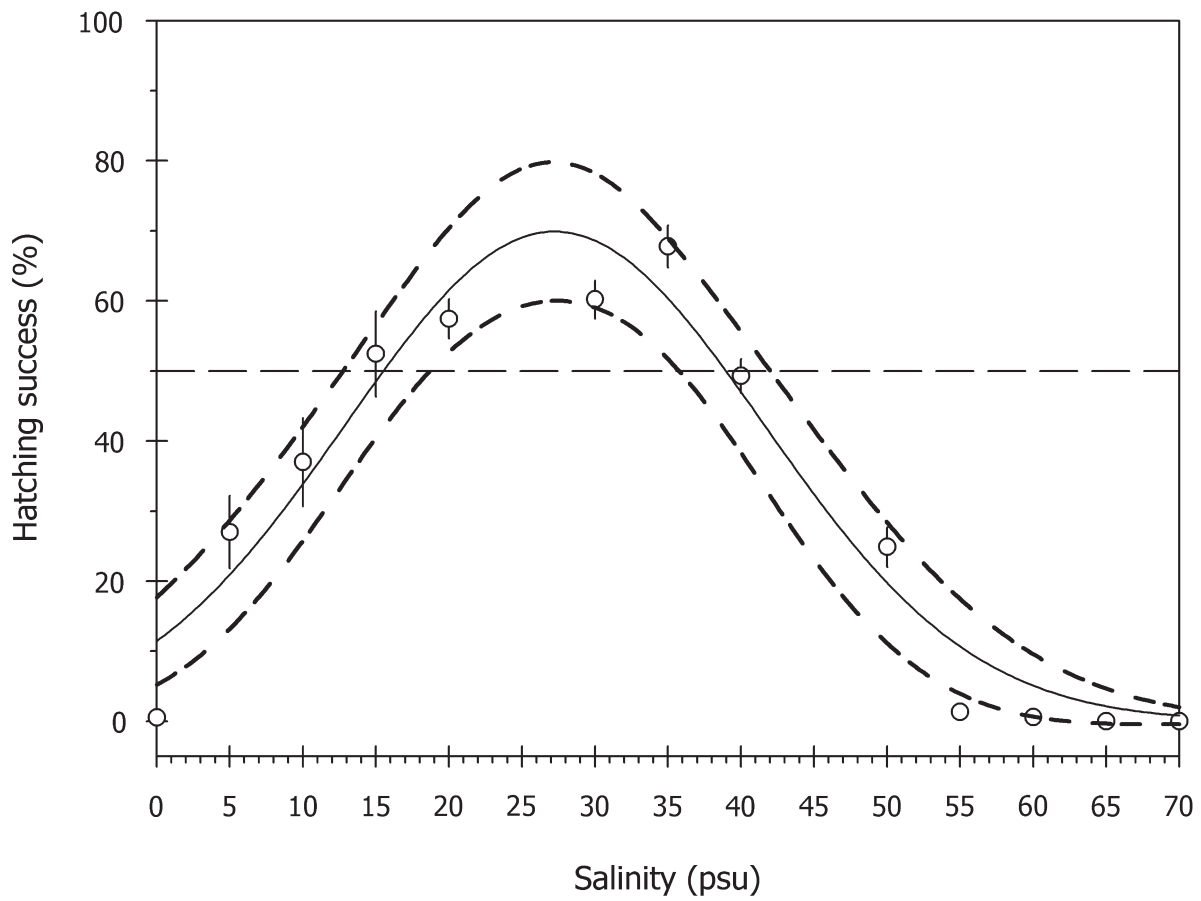

FIGURE 3. The optimum salinity for hatching of A. tonsa eggs is $27.5 \mathrm{psu}$, with a $67.7 \%$ hatching success. Eggs from this A. tonsa strain are not capable of hatching at salinities above 55 psu. Symbols are mean values $\pm S E(\mathrm{n}=10$ or 20). The horizontal dashed line shows a 50\% cutoff for hatching success, we considered hatching of $50 \%$ and more as an acceptable hatching success in practice. The solid line is a three parameter Gaussian fit and dashed lines are 95\% CL.

probably related to that $\mathrm{MgSO}_{4}$ was the source used as addition when formulating the salts by the manufacturer. Another observed difference was the $\mathrm{Ca}^{2+}$ content where especially RS has a low content which will potentially affect the buffering capacity and alkalinity of the saltwater when using this salt (Atkinson and Bingman 1997). Very few studies exist comparing different commercial salts and no specific study on microalgae and copepods has been found (Soundarapandian et al. 1994). However, discussing rearing of microalgae and copepods with the scientific community and aquarists all have a gut feeling that sea salts originating from evaporated SW have a better trace ion composition than rock salt and underground water extraction because ions are lost in the geological processes involved in the latter. 

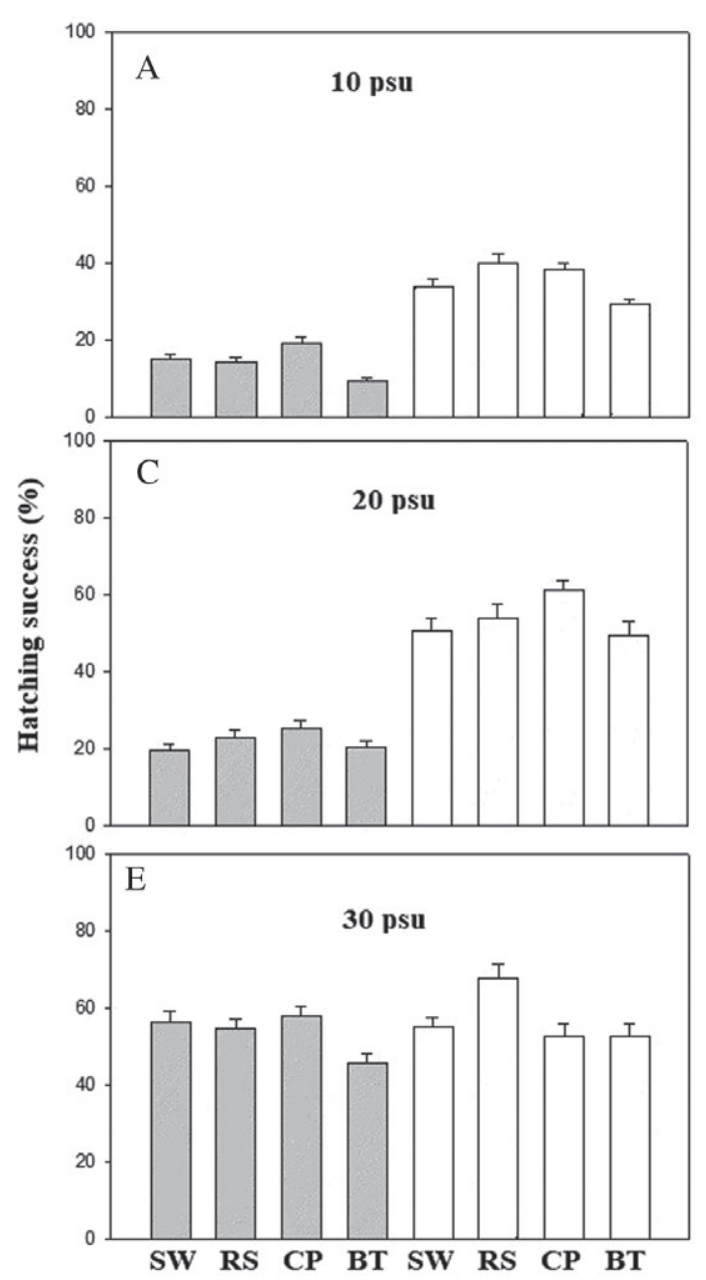
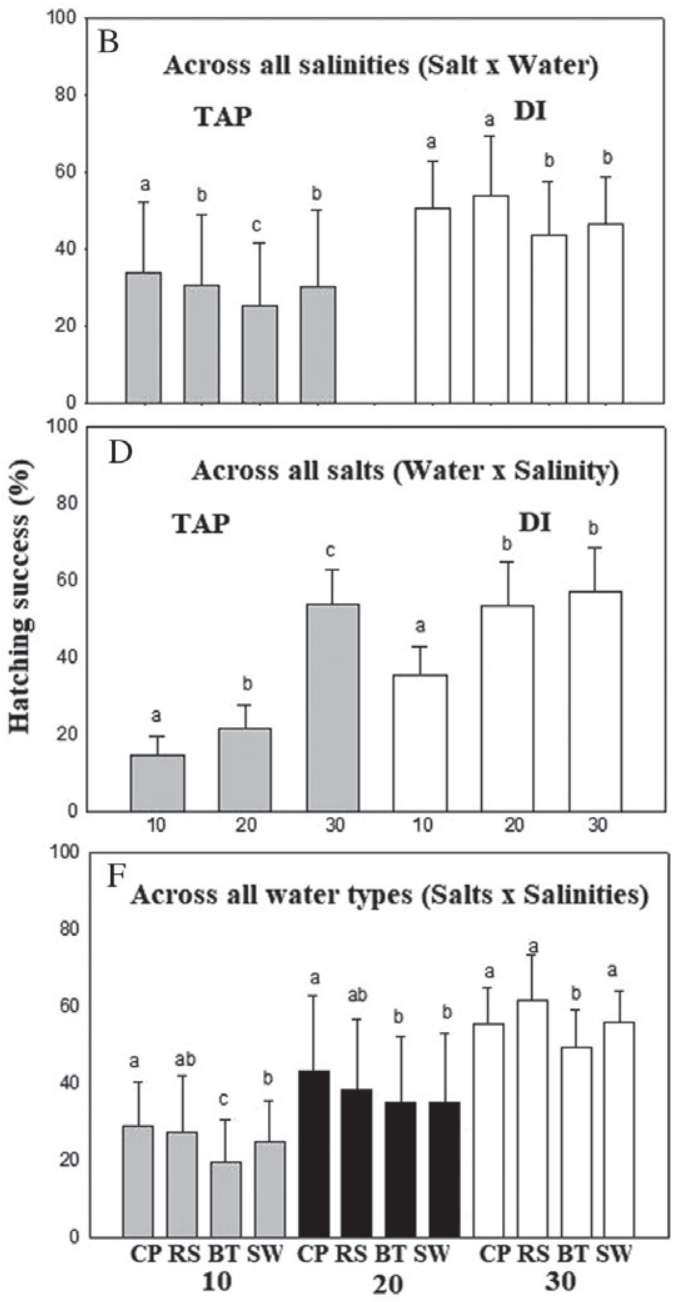

FIGURE 4. Hatching success by A. tonsa eggs as a function of salt, water, and salinity. (A-E) Gray bars are salts mixed with ordinary tap water and white bars are salts diluted in deionized water. $(F)$ Gray bars are 10 psu, black bars are 20 psu, and white bars are $30 \mathrm{psu}$. Bars are mean $\pm S D(\mathrm{n}=4)$. Panels $(A-C)$ show single effects, whereas $(D-F)$ show mixed effects.

\section{Microalgae}

Rhodomonas salina can grow in all the tested salt products dissolved in both water types. Tap water varies in potential contaminants, alkalinity, pesticides, and volatile organic compounds depending on the source of the water (DeSimone 2009). Therefore, producers of commercial salts recommend that they are mixed with reverse osmosis water or DI water. In our experiment, we found that growth of $R$. salina was lower in tap water than in DI water and we speculate that this is an effect of various unknown impurities in the local tap water used, although no differences were observed in the ion composition analyses of the tap water (Table 1).

The $R$. salina growth rates $(0.8-1.2 / \mathrm{d})$ were similar or slightly higher than those reported in the literature (Lewitus and Caron 1990; Bartual et al. 2002; Hammer et al. 2002; Lafarga-De la Cruz et al. 2006; Vu et al. 2015). The important ions in relation to growth are the excess of $\mathrm{NH}_{4}$ in the $\mathrm{SW}, \mathrm{CP}$, and BT as $\mathrm{NH}_{4}$ is a state of nitrogen that is easy for the algae to take up and assimilate (Rückert and Giani 2004; Table 1). 
TABLE 3. Results from a three-way factual PERMANOVA analyzes, showing effects on copepod eggs hatching success. ${ }^{a}$

\begin{tabular}{lcccccc}
\hline Source & df & SS & MS & Pseudo- $F$ & $P($ perm $)$ & Unique perms \\
\hline Salt & 3 & 23439 & 0.7813 & 18349 & $<\mathbf{0 . 0 0 0 1}$ & 9947 \\
Water & 1 & 22207 & 22207 & 521.51 & $\mathbf{< 0 . 0 0 0 1}$ & 9823 \\
Salinity & 2 & 31091 & 15545 & 365.08 & $\mathbf{< 0 . 0 0 0 1}$ & 9944 \\
Salt $\times$ water & 3 & 0.4023 & 0.13411 & 31496 & $\mathbf{< 0 . 0 2 4 9}$ & 9950 \\
Salt $\times$ salinity & 6 & 10071 & 0.16785 & 39418 & $\mathbf{< 0 . 0 0 1 6}$ & 9929 \\
Water $\times$ salinity & 2 & 91963 & 45981 & 107.99 & $\mathbf{< 0 . 0 0 0 1}$ & 9953 \\
Salt $\times$ water $\times$ salinity & 6 & 0.3799 & 633,13 & 14869 & 0.1827 & 9962 \\
Residual & 216 & 91975 & 425,81 & & & \\
Total & 239 & 75824 & & & & \\
\hline
\end{tabular}

${ }^{a}$ Results from a three-factual Permanova analyses effects on hatching success of commercial salts, which water the salts, were diluted in and salinity. Statistical significances are marked in bold font $(P<0.05)$.

Therefore, this extra nitrogen source could have an additive effect on the $\mathrm{f} / 2$ media (Guillard and Ryther 1962). Thoisen et al. (2018) showed that statistically significant higher growth rates of $R$. salina (K-1487) were obtained when cultivated with $\mathrm{f} / 2$ growth medium with ammonium compared to nitrate as the prime N-source. However, this does not explain the algae growth rates in water mixed with $\mathrm{RS}$ as only trace amounts of $\mathrm{NH}_{4}$ were detected in this salt (Table 1). The primary environmental variables that control microalgae growth are irradiance levels and nutrient levels (Lafarga-De la Cruz et al. 2006). In the current experiment, both light and nutrients were supplied in excess, which will promote optimal growth rates. However, we are aware that it is difficult to compare growth rates between experiments as even small variations in growth conditions, algal strain selection, and abiotic conditions will render a different result.

Marine microalgae have different protection mechanisms to cope with changes in salinity of the surrounding environment (Gebser 2015). Adaptations to varying salinities therefore often depend on the ecological habitat the microalgae inhabit in nature. $R$. salina is ecologically a brackish water species; so a widespread tolerance to different salinities is to be expected, as shown by Cañavate and Lubian (1995), where the authors reported that Rhodomonas baltica was able to sustain rapid changes $(24 \mathrm{~h})$ from 36 to $20 \mathrm{psu}$. In short, the $R$. salina strain tested in this experiment had an optimal salinity of 29.1 psu but can be adapted to grow well in a very broad range of 5-50 psu.

\section{Copepods}

Optimal egg hatching success of $67.7 \%$ occurred at a salinity of $27 \mathrm{psu}$. The hatching success corresponded to values reported in the literature (Drillet et al. 2006b; Peck et al. 2015). Peck and Holste (2006) showed that besides salinity, the length of the period of cold storage of eggs had a negative effect on their hatching success. The optimal hatching in the present study corresponds to the response of eggs stored for between 100 and 150 days in the Peck and Holste (2006) study, although the eggs in the present study were less than $4 \mathrm{~h}$ old. However, we have often observed variation in egg hatching success among batches (Højgaard et al. 2008). Eggs exposed to a salinity below 15 psu still hatch and even eggs exposed to a salinity of 0 psu have earlier been shown to hatch when transferred to higher salinities (Højgaard et al. 2008). Another study showed that eggs that were shock-treated with a high salinity $(20 \mathrm{~min}$ of exposure) could sustain salinities up to $100 \mathrm{psu}$ without a subsequent decrease in hatching success (Ohs et al. 2009). The capability of the eggs to survive in extreme salinities can be explained by the protecting function of the embryonic membrane and by the capability of the eggs to enter into a quiescent stage (Højgaard et al. 2008; Hansen et al. 2012). Within a salinity range from 15 to $40 \mathrm{psu}$, the hatching rate of the eggs was $50 \%$ or higher. Hatching rates above $50 \%$ are considered feasible in aquaculture and we recommend to culture A. tonsa within this salinity range. This salinity range was also considered where the egg hatching exhibited a large 


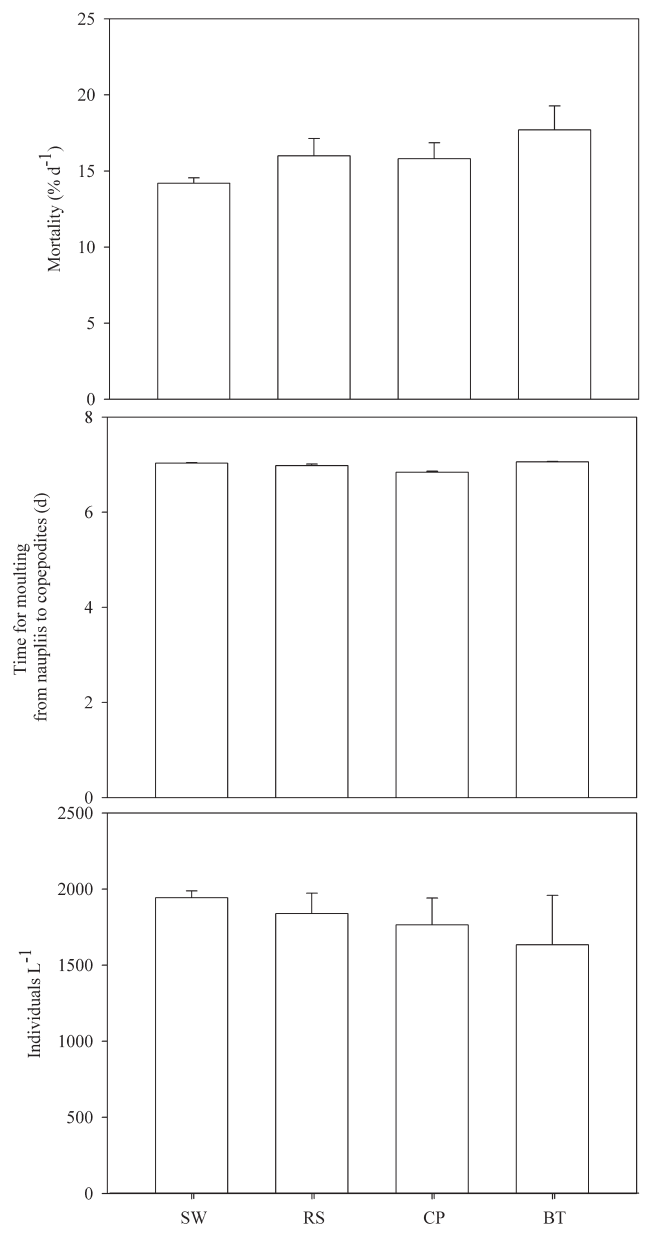

FIGURE 5. Daily mortality by A. tonsa in different treatments expressed in \%/d (mean $\pm S E, \mathrm{n}=4$, top panel). Development time for switch from nauplii stages to copepodite stages, expressed in d (mean $\pm S E, \mathrm{n}=4$, middle panel). Individuals/L at the end of the experiment (average $\pm S E, \mathrm{n}=4$, bottom panel).

plasticity, which did not cause any significant loss in viability of the eggs. Physiologically, it is reasonable to assume that the immobile egg stage is potentially more plastic than the mobile nauplii and copepodites stages to changes in salinity.

The results showed a decreased hatching effect of lower salinity regardless of salt type. The decreased hatching success was not observed at $30 \mathrm{psu}$ with salts diluted with tap water. It is well known that high levels of ions present in SW act as a protecting factor against metal toxicity because of metal complexation with anions, especially chloride, and we speculate that this is the same type of effect as observed in the present study (Monteiro et al. 2013). So, the potential negative effects from tap water are diluted by increased salinity, hence adding more ions to the water. Investigating the effects of different salts on hatching success, BT was the salt that in most cases resulted in low hatching. We, therefore, recommend not using BT and for full precautionary effects no other mined and synthetic salts for hatching of A. tonsa eggs for aquaculture. BT was the salt with the lowest ion content and we therefore speculate that this slightly reduced amount of ions caused the observed effects (Monteiro et al. 2013). As we found such a profound effect of tap water on the hatching success, we excluded tap water for the further study on survival and development of nauplii and copepodites.

Table 1 showed that RS was the most unbalanced salt when compared to SW and the other two salts. The hardness of water is normally defined by the ion strength of $\mathrm{Ca}^{2+}$ and $\mathrm{Mg}^{2+}$. RS had the lowest observed content of $\mathrm{Ca}^{2+}$ $(2.9 \mathrm{mmol} / \mathrm{kg})$, whereas three times higher content of $\mathrm{Mg}^{2+}$ was observed. Combined higher concentrations of these ions are known to lower metal toxicity and we therefore speculate if the more successful rearing of $A$. tonsa in RS than in the other salts is a result of reduced metal toxicity (Erickson et al. 1996). We are not aware of any study showing the single effect of $\mathrm{Ca}^{2+}$ on copepods. In Daphnia, low amounts of calcium have shown an effect on calcification and the same could be expected for freshwater copepods, but we do not expect this to be a problem for marine copepods as the general calcium pool there is significantly higher when compared to freshwater (Alstad et al. 1999).

The copepod mortality in the present study was approximately $15 \% / d$ and was not significantly different among treatments. Other studies have shown mortalities around $4-5 \% / \mathrm{d}$ for this strain of A. tonsa in culture (Berggreen et al. 1988; Drillet et al. 2008, 2015). Although the mortality was relatively high in the present study, this has been reported before by our research team even with mortalities up to 17\%/d (Jepsen et al. 2007). It has been speculated that elevated 
mortality is a stress response from experimental handling (Jepsen et al. 2007). This hypothesis could be tested in future studies as recent scientific efforts have discovered stress-related proteins in A. tonsa, which is a relevant tool for embryonic and free-living Acartia stress monitoring (Tartarotti and Torres 2009; Nilsson et al. 2014). The copepod development rates were not different among the four treatments at approximately $7 \mathrm{~d}$ between moulting from nauplii to copepodite stage I, which is in agreement with previous studies that have reported time between moults of the same strain of $A$. tonsa in the range of $6.25-8 \mathrm{~d}$ with the same temperatures as in the present study (Berggreen et al. 1988; Drillet et al. 2008). No study has been identified that reports time for moult or stage development as a function of salinity. Instead, Peck and Holste (2006) reported egg production as a function of salinity to be optimal at $15 \mathrm{psu}$. As specific egg production is equal to specific somatic growth and thereby development (according to Berggreen et al. 1988), we anticipate that A. tonsa in the present experiment would have developed faster in lower salinity (15-20 psu). It can be hypothesized that salinities in this range are probably close to the osmolality of adult $A$. tonsa and they thereby save energy on hyporegulation and instead allocate it to somatic growth/egg production (Farmer 1980; Svetlichny and Hubareva 2014).

\section{Conclusions}

In conclusion, we found that water type, salts, and salinity had effects on the growth of both $R$. salina and A. tonsa.

Overall, it is indeed possible to produce both $R$. salina and $A$. tonsa with commercial salts, different water types, and various salinities. To ensure optimal outcome, we had best success using DI water mixed with RS and at a salinity of 28 psu as a compromise between the growth optimums of $R$. salina and A. tonsa.

\section{Acknowledgments}

This work was funded by the Danish Council for Strategic Research IMPAQ grant (J. no.
10-093522) and Innovation Fund Denmark COMA (grant no. 67-2013-1) to B.W.H. Further, P.M.J. wishes to thank two student groups, Amanda Hansen, Álfheiður E. Guðmundsdóttir, Aske Hansen, Casper D. Læssøe, Ida Kyhnauv, Jeanne Frost, Jens-Peter Paulsen, Katrine N. Jørgensen, Malte J. Hansen, Mikkel S. Bennetsen, and Sara N. Grønlund, for their enthusiastic help with providing algae results. The laboratory technicians Anne B. Faarborg and Rikke Guttesen are acknowledged for managing students and assisting with the laboratory work, and Gitte $\mathrm{K}$. Bøg is acknowledged for analyzing water samples for ion composition.

\section{Literature Cited}

Abate, T. G., R. Nielsen, M. Nielsen, G. Drillet, P. M. Jepsen, and B. W. Hansen. 2015. Economic feasibility of copepod production for commercial use: result from a prototype production facility. Aquaculture 436: $72-79$.

Alstad, N. E., L. Skardal, and D. O. Hessen. 1999. The effect of calcium concentration on the calcification of Daphnia magna. Limnology and Oceanography 44(8):2011-2017.

Aquaseasalt. 2017. Accessed Nov. 28, 2017 at www .aquaseasalt.net

Arndt, C. and U. Sommer. 2014. Effect of algal species and concentration on development and fatty acid composition of two harpacticoid copepods, Tisbe sp. and Tachidius discipes, and a discussion about their suitability for marine fish larvae. Journal of Aquaculture Nutrition 20:44-59.

Atkinson, M. J. and C. Bingman. 1997. Elemental composition of commercial seasalts. Journal of Aquariculture and Aquatic Sciences 8(2):39-43.

Bartual, A., L. M. Lubián, J. A. Gálvez, and F. X. Niell. 2002. Effect of irradiance on growth, photosynthesis, pigment content and nutrient consumption in dense cultures of Rhodomonas salina (Wislouch) (Cryptophyceae). Ciencias Marinas 28: 381-392.

Berggreen, U., B. Hansen, and T. Kiørboe. 1988. Food size spectra, ingestion and growth of the copepod Acartia tonsa during development: implications for determination of copepod production. Marine Biology 99(3):341-352.

Cañavate, J. P. and L. M. Lubian. 1995. Relationship between cooling rates, cryoprotectant concentrations and salinities in the cryopreservation of marine microalgae. Marine Biology 124:325-334.

Cervetto, G., R. Gaudy, and M. Pagano. 1999. Influence of salinity on the distribution of Acartia tonsa (Copepoda, Calanoida). Journal of Experimental Marine Biology and Ecology 239(1):33-45. 
Chinnery, F. E. and J. A. Williams. 2004. The influence of temperature and salinity on Acartia (Copepoda: Calanoida) nauplii survival. Marine Biology 145(4):733-738.

DeSimone, L.A. 2009. Quality of water domestic wells in principal aquafers of the United States, 1991-2004. U.S. Geological Survey Scientific Investigations Report 2008-5227; 0-139 pp, Library of Congress, USA.

Dhert, P., G. Rombaut, G. Suantika, and P. Sorgeloos. 2001. Advancement of rotifer culture and manipulation techniques in Europe. Aquaculture 200:129-146.

Drikkevandsbekendtgørelsen. 2016. Accessed Sept. 29, 2017 at http://www.retsinformation.dk/Froms/R0710 .aspx $? \mathrm{id}=180348$

Drillet, G., N. O. G. Jørgensen, T. F. Sørensen, H. Ramløv, and B. W. Hansen. 2006a. Biochemical and technical observations supporting the use of copepods as live feed organisms in marine larviculture. Aquaculture Research 37(8):756-772.

Drillet, G., M. H. Iversen, T. F. Sørensen, H. Ramløv, T. Lund, and B. W. Hansen. 2006b. Effect of cold storage upon eggs of a calanoid copepod, Acartia tonsa (Dana) and their offspring. Aquaculture 254(1):714-729.

Drillet, G., P. M. Jepsen, J. K. Højgaard, N. O. G. Jørgensen, and B. W. Hansen. 2008. Strain-specific vital rates in four Acartia tonsa cultures II: life history traits and biochemical contents of eggs and adults. Aquaculture 279(1):47-54.

Drillet, G., M. Rais, A. Novac, P. M. Jepsen, M. S. Mahjoub, and B. W. Hansen. 2015. Total egg harvest by the calanoid copepod Acartia tonsa (Dana) in intensive culture-effects of high stocking densities on daily egg harvest and egg quality. Aquaculture Research 46(12):3028-3039.

Erickson, R. J., D. A. Benoit, V. R. Mattson, E. N. Leonard, and H. P. Nelson. 1996. The effects of water chemistry on the toxicity of copper to fathead minnows. Environmental Toxicology and Chemistry 15(2): 181-193.

Farmer, L. 1980. Evidence for hyporegulation in the calanoid copepod, Acartia tonsa. Comparative Biochemistry and Physiology Part A: Molecular and Integrative Physiology 65(3):359-362.

Gebser, B. (2015). Osmoregulation of microalgae and release of climate relevant gases. $\mathrm{PhD}$ dissertation. Chemisch-Geowissenschaftlichen Fakultet, Frederich-Schiller Universitat Jena.

González-Araya, R., L. Lebrun, C. Quéré, and R. Robert. 2012. The selection of an ideal diet for Ostrea edulis (L.) broodstock conditioning (part B). Aquaculture 362-363:55-66.

Guevara, M., L. Bastardo, R. Cortez, B. Arredondo-Vega, L. Romero, and P. Gómez. 2011. Pastas de Rhodomonas salina (Cryptophyta) como alimento para Brachionus plicatilis (Rotifera). Revista de Biología Tropical 59(4):1503-1515.

Guillard, R. R. L. and J. H. Ryther. 1962. Studies of marine planktonic diatoms. I. Cyclotella nana Hustedt and Detonula confervacea Cleve. Canadian Journal of Microbiology 8:229-239.

Hammer, A., R. Schumann, and H. Schubert. 2002. Light and temperature acclimation of Rhodomonas salina (Cryptophyceae): photosynthetic performance. Aquatic Microbial Ecology 29:287-296.

Hansen, B. W., G. Drillet, K. P. Sjøgren, and B. Vismann. 2012. Do Acartia tonsa (Dana) eggs regulate their volume and osmolality under as salinity changes? Journal of Comparative Physiology B 182:613-623.

Hansen, B. W., P. J. Hansen, T. G. Nielsen, and P. M. Jepsen. 2017. Effects of elevated $\mathrm{pH}$ on marine copepods in mass cultivation systems - practical implications. Journal of Plankton Research 39:984-993. https://doi.org/10.1093/plankt/fbx032.

Højgaard, J. K., P. M. Jepsen, and B. W. Hansen. 2008. Salinity induced quiescence in eggs of the calanoid copepod Acartia tonsa (Dana): a simple method for egg storage. Aquaculture Research 39(8):828-836.

Jepsen, P. M., N. Andersen, T. Holm, A. T. Jørgensen, J. K. Højgaard, and B. W. Hansen. 2007. Effects of adult stocking density on egg production and viability in cultures of the calanoid copepod Acartia tonsa (Dana). Aquaculture Research 38(7):764-772.

Jepsen, P. M., C. V. Andersen, J. Schjelde, and B. W. Hansen. 2015. Tolerance of un-ionized ammonia in live feed cultures of the calanoid copepod Acartia tonsa Dana. Aquaculture Research 46(2):420-431.

Kiørboe, T., F. Møhlenberg, and K. Hamburger. 1985. Bioenergetics of the planktonic copepod Acartia tonsa: relation between feeding, egg production and respiration, and composition of specific dynamic action. Marine Ecology Progress Series 26(1-2):85-97.

Klein Breteler, W., M. Koski, and S. Rampen. 2004. Role of essential lipids in copepod nutrition: no evidence for trophic upgrading of food quality by a marine ciliate. Marine Ecology Progress Series 274:199-208.

Knuckey, R. M., G. L. Semmens, R. J. Mayer, and M. A. Rimmer. 2005. Development of an optimal microalgal diet for the culture of the calanoid copepod Acartia sinjiensis: effect of algal species and feed concentration on copepod development. Aquaculture 249(1):339-351.

Kusk, K. O. and L. Wollenberger. 1999. Fully defined saltwater medium for cultivation of and toxicity testing with marine copepod Acartia tonsa. Environmental Toxicology and Chemistry 18(7):1564-1567.

Lafarga-De la Cruz, F., E. Valenzuela-Espinoza, R. Millán-Núñez, C. C. Trees, E. Santamaría-delÁngel, and F. Núñez-Cebrero. 2006. Nutrient uptake, chlorophyll a and carbon fixation by Rhodomonas sp. (Cryptophyceae) cultured at different irradiance and nutrient concentrations. Aquaculture Engineering 35:51-60.

Lewitus, A. J. and D. A. Caron. 1990. Relative effects of nitrogen or phosphorus depletion and light intensity on the pigmentation, chemical composition, and volume of Pyrenomonas salina (Cryptophyceae). Marine Ecology Progress Series 61:171-181. 
Mahjoub, M. S., C. Schmoker, and D. Drillet. 2013. Live feeds in larval fish rearing: production, use, and future. Pages 41-71 in J. G. Qin, editor. Larval fish aquaculture. Nova Publishers.

Marcus, N. H., C. Richmond, C. Sedlacek, G. A. Miller, and C. Oppert. 2004. Impact of hypoxia on the survival, egg production and population dynamics of Acartia tonsa Dana. Journal of Experimental Marine Biology and Ecology 301(2):111-128.

Monteiro, S. C. R., G. L. L. Pinho, K. Hoffmann, I. F. Barcarolli, and A. Bianchini. 2013. Acute waterborne copper toxicity to the euryhaline copepod Acartia tonsa at different salinities: influence of natural freshwater and marine dissolved organic matter. Environmental Toxicology and Chemistry 32(6):1412-1419.

Nilsson, B., P. M. Jepsen, K. Rewitz, and B. W. Hansen. 2014. Expression of hsp70 and ferritin in embryos of the copepod Acartia tonsa (Dana) during transition between subitaneous and quiescent state. Journal of Plankton Research 36(2):513-522.

Ohs, C. L., A. L. Rhyne, and E. Stenn. 2009. Viability of subitaneous eggs of the copepod, Acartia tonsa (Dana), following exposure to various cryoprotectants and hypersaline water. Aquaculture 287(1):114-119.

Ohs, C. L., K. L. Chang, S. W. Grabe, M. A. DiMaggio, and E. Stenn. 2010. Evaluation of dietary microalgae for culture of the calanoid copepod Pseudodiaptomus pelagicus. Aquaculture 307(3):225-232.

Paffenhöfer, G., D. E. Stearns. 1988. Why is Acartia tonsa (Copepoda: Calanoida) restricted to nearshore environments? Marine Ecology Progress Series 42(1):33-38.

Peck, M. A. and L. Holste. 2006. Effects of salinity, photoperiod and adult stocking density on egg production and egg hatching success in Acartia tonsa (Calanoida: Copepoda): optimizing intensive cultures. Aquaculture 255(1):341-350.

Peck, N., J. Peters, R. Diekmann, S. Laakmann, and J. Renz. 2015. Interactive effects of temperature and salinity on population dynamics of the calanoid copepod Acartia tonsa. Journal of Plankton Research 37(1):197-210

RedSea. 2017. Accessed Nov. 28, 2017 at https:// www.redseafish.com/red-sea-salts/red-sea-salt/\# prettyPhoto

Riisgård, H. U., P. P. Egede, and I. B. Saavedra. 2011. Feeding behaviour of the mussel, Mytilus edulis: new observations, with a minireview of current knowledge. Journal of Marine Biology. https://doi.org/10.1155/ 2011/312459.

Rückert, G. V. and A. Giani. 2004. Effect of nitrate and ammonium on the growth and protein concentration of Microcystis viridis Lemmermann (Cyanobacteria). Brazilian Journal of Botany 27:325-331.
Shields, R. J., J. G. Bell, F. S. Luizi, B. Gara, N. R. Bromage, and J. R. Sargent. 1999. Natural copepods are superior to enriched Artemia nauplii as feed for halibut larvae (Hippoglossus hippoglossus) in terms of survival, pigmentation and retinal morphology: relation to dietary essential fatty acids. Journal of Nutrition 129(6):1186-1194.

Soundarapandian, P., M. J. Samuel, and T. Kannupandi. 1994. Commercial production of Macrobrachium malcolmsonii seeds using synthetic water and crude common salt. Mahasagar 27(2):139-142.

Støttrup, J. G. and J. Jensen. 1990. Influence of algal diet on feeding and egg-production of the calanoid copepod Acartia tonsa Dana. Journal of Experimental Marine Biology and Ecology 141(2-3):87-105.

Støttrup, J. G., K. Richardson, E. Kirkegaard, and N. J. Pihl. 1986. The cultivation of Acartia tonsa Dana for use as a live food source for marine fish larvae. Aquaculture 52(2):87-96.

Stumm, W. and J. J. Morgan. 1996. Aquatic chemistry. Wiley Interscience, New York, New York, USA.

Svetlichny, L. and E. Hubareva. 2014. Salinity tolerance of alien copepods Acartia tonsa and Oithona davisae in the Black Sea. Journal of Experimental Marine Biology and Ecology 461:201-208.

Tartarotti, B. and J. J. Torres. 2009. Sublethal stress: impact of solar UV radiation on protein synthesis in the copepod Acartia tonsa. Journal of Experimental Marine Biology and Ecology 375(1-2):106-113.

Thoisen, C. V., M. T. T. Vu, T. Carron-Cabaret, P. M. Jepsen, S. L. Nielsen, and B. W. Hansen. (Accepted). Small-scale experiments to improve large-scale production of the microalga Rhodomonas salina for live feed in aquaculture. Journal of Applied Phycology.

Turingan, R. G., J. L. Beck, J. M. Krebs, and J. D. Licamele. 2005. Development of feeding mechanics in marine fish larvae and the swimming behavior of zooplankton prey: implications for rearing marine fishes. Pages 119-132 in C.-S. Lee, P. J. O'Bryen, and N. H. Marcus, editors. Copepods in aquaculture. Blackwell Publishing Ltd, Oxford, UK.

Vu, M. T. T., C. Douëtte, T. A. Rayner, C. Thoisen, S. L. Nielsen, and B. W. Hansen. 2015. Optimization of photosynthesis, growth, and biochemical composition of the microalga Rhodomonas salina - an established diet for live feed copepods in aquaculture. Journal of Applied Phycology 28(3):1485-1500.

Zhang, J., C. Wu, D. Pellegrini, G. Romano, F. Esposito, A. Ianora, and I. Buttino. 2013. Effects of different monoalgal diets on egg production, hatching success and apoptosis induction in a Mediterranean population of the calanoid copepod Acartia tonsa (Dana). Aquaculture 400:65-72. 